\title{
Partial genome analysis of cox1 subunit-I region in mitochondrial DNA of canine mammary tumours
}

\author{
K. Krithiga', Arathi Rajan', Geetu Rose Varghese', R.L. Neetha', Dipyaman Patra', \\ Neethu Krishnan ${ }^{1}$, Arathy Warrier ${ }^{1}$ and Priya Srinivas ${ }^{2}$ \\ CRP-6, Rajiv Gandhi Centre for Biotechnology, Research Centre, \\ University of Kerala, Thiruvananthapuram
}

Citation: Krithiga, K., ArathiRajan, Geetu Rose Varghese, Neetha, R.L., DipyamanPatra, Neethu Krishnan, ArathyWarrier and PriyaSrinivas. Partial genome analysis of Cox1 subunit-I region in mitochondrial DNA of canine mammary tumours. J. Vet. Anim. Sci. 52(1): 95-98.

DOI: https://doi.org/10.51966/jvas.2021.52.1.95-98

Received: 25.09.2020

Accepted: 14.10 .2020

Published: 01.01.2021

\begin{abstract}
Oncogenesis is an area which continuously elicits research interest. There are innumerable factors which contribute to oncogenesis of which mitochondrial DNA (mtDNA) mutations play a major role. Though extensive studies have been conducted relating mtDNA mutations to human cancers, there is sparse information available on canine neoplasia. Cytochrome oxidase1 (COX1) is an important component of electron transport chain of mitochondria and any alteration in it would result in altered energy production which is very essential for proliferating neoplastic cells. Two samples of canine mammary carcinomas (CMT) were subjected to partial genome sequencing of COX1 subunit -I. There was no change in the gene sequence of COX1. Further studies in this aspect would pave the way for investigations on the role of mtDNA mutation in oncogenesis and could provide insights into how canines can serve as models for human cancers.
\end{abstract}

Keywords: Canine mammary tumour, mtDNA, mutation

The quest to unravel the secret of neoplastic transformation has not left any stone unturned. More than eighty years ago, Otto Warburg, in 1956, described the accelerated aerobic glycolysis in neoplastic cells despite the presence of oxygen (Warburg effect). This process helps neoplastic cells to maintain their vitality, ability to proliferate, invade and evade apoptosis. (GrzybowskaSzatkowska and Slaska, 2012). Cytochrome c oxidase (COX) is one of the five-member protein complex involved in oxidative phosphorylation resulting in energy production and forms an integral part of mtDNA. COX1 upregulation has been reported in breast cancers when compared to normal tissues (Haakensen et al., 2011). The mtDNA are said to be more prone to mutations due to their lack

1. PhD Scholars

2. Scientist F, Rajiv Gandhi Centre for Biotechnology, Research Centre, University of Kerala, Thiruvananthapuram Corresponding author: priyasrinivas@rgcb.res.in

Copyright: () 2021 Krithiga et al. This is an open access article distributed under the terms of the Creative Commons Attribution 4.0 International License (http://creativecommons.org/licenses/by/4.0/), which permits unrestricted use, distribution, and reproduction in any medium, provided the original author and source are credited. 
Fig.1. Histopathological observations of the two samples of CMT

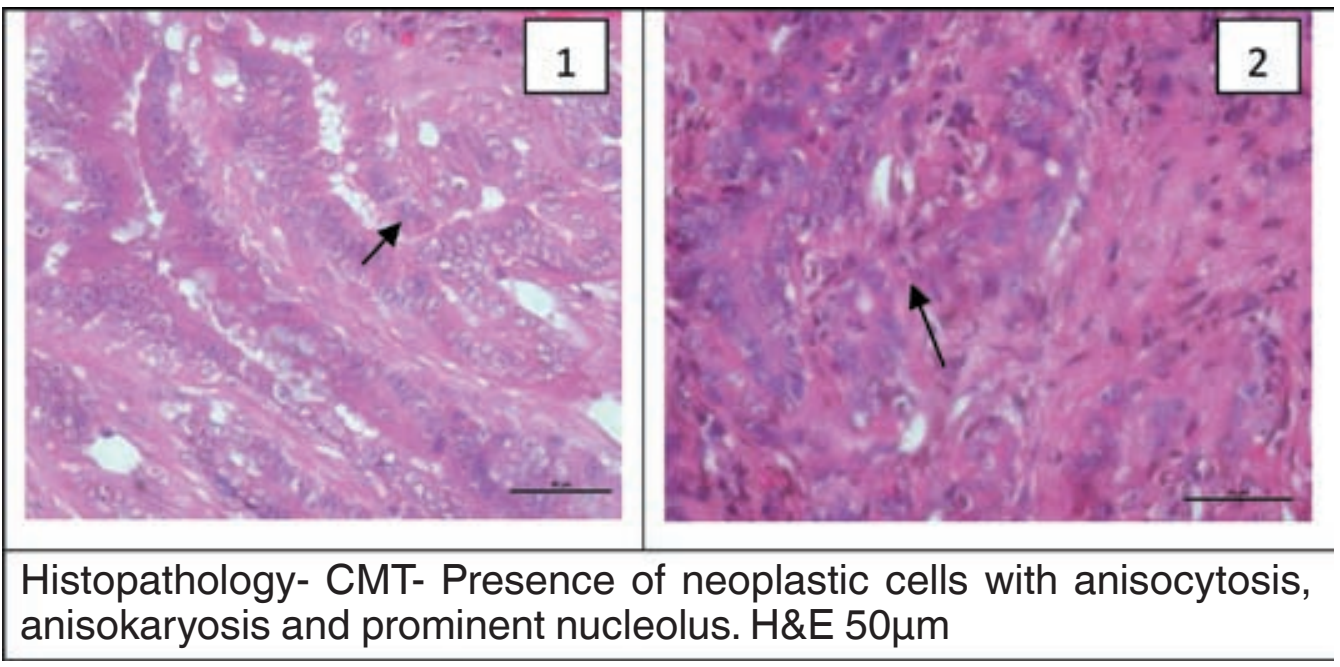

Fig.2. NCBI BLASTn analysis showing 100\% identity between COX1 sequence from CMT case 1 and the reference sequence MN542345.1 from Canis lupus familiaris isolate 38 cytochrome c oxidase subunit 1 (COI) gene, partial cds.
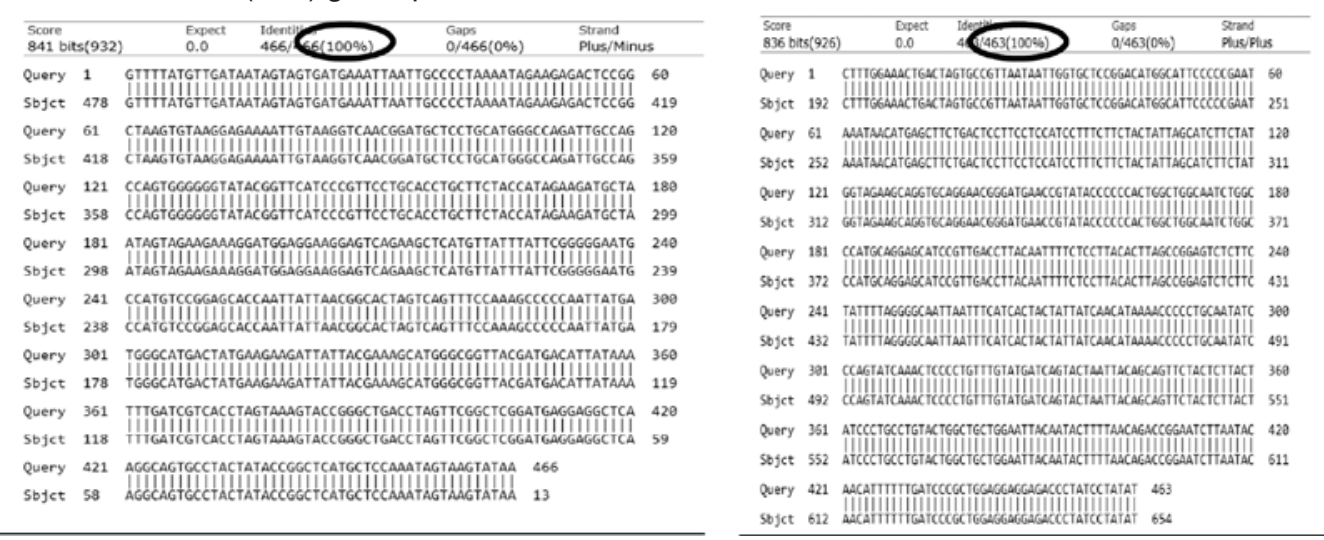

of protective histones, compromised DNA repair mechanism and exposure to free radical injury during oxidative phosphorylation (Miyazono et al., 2002). Though somatic mtDNA mutations have been reported in canine neoplastic transformations (Slaska et al., 2015), very few studies have focussed on the role of COX1 in canine mammary tumours (CMT). Hence this study was done as a preliminary one employing two cases of CMT to gain insights into the role of COX1 subunit-I sequence variations in CMT, using next generation sequencing.

The samples included in the study were two CMT resected masses which were collected with the owner's consent. Tissue samples were collected in 10 per cent Neutral Buffered Formalin (NBF) for histopathological analysis (Bancroft and Gamble, 2008). Samples were also preserved in ethanol for sequencing studies. Genomic DNA was isolated from the tissues using NucleoSpin® Tissue Kit (Macherey-Nagel) following the manufacturer's instructions. The PCR amplification for COX1 (Folmer et al., 1994) was performed using PCR thermal cycler (GeneAmp PCR System 9700, Applied Biosystems) using the forward primer JGLCO F (5'-TITCIACIAAYCAYAARGAYATTGG-3') and reverse primer JGLCO $\mathrm{R}$ (5'- 
TAIACYTCIGGRTGICCRAARAAYCA -3'). The removal of unwanted primers and dNTPs from a PCR product mixture was done using ExoSAP-IT (GE Healthcare). After the clean-up, sequencing reaction was done in a PCR thermal cycler (GeneAmp PCR System 9700, Applied Biosystems) using the BigDye Terminator v3.1 Cycle Sequencing Kit (Applied Biosystems, USA) following the manufacturer's protocol. Mitochondrial genome sequence of $466 \mathrm{nt}$ from one sample and $463 \mathrm{nt}$ in the other sample were analysed against standard sequences available in the NCBI database using the BLAST tool.

The tumours were subjected to histopathology and were found to be carcinomas as depicted in Fig.1. In this study, two canine cancer tissues were analysed to study whether mtDNA mutations in CMTs had any significant role to play in tumorigenesis. The sequences obtained from both the cases of CMT blasted using NCBI BLASTn revealed 100 per cent identity with the prevailing GenBank submissions of partial mitochondrial genomes of Canis lupus familiaris. The BLAST result in both samples did not show any variation in the COX1 subunit I as represented in Fig.2.

There have been reports on COX1 mutation in many human cancers including prostate cancers and breast cancers (Petros et al., 2005 and Omasanggar et al., 2020). However, the partial genome analysis of COX1 subunit $I$ in the two samples did not show any variation. Further studies involving the whole genome of mtDNA and corresponding normal tissues in CMT patients may shed more light on the role of mtDNA mutations in carcinogenesis. As only two samples were analysed, a detailed analysis with more number of samples with complete mtDNA analysis will provide more authentic data to confirm its statistical significance. This study also sheds light on the possibility of analysing CMTs as a model to study mtDNA biology in human breast cancers.

\section{Acknowledgement}

We hereby acknowledge the Regional Facility for DNA Fingerprinting, Rajiv Gandhi Centre for Biotechnology, Thiruvananthapuram, for their valuable help in carrying out the sequencing. We also acknowledge the University of Kerala, Intra-mural funding Rajiv Gandhi Centre for Biotechnology and Kerala Veterinary and Animal Sciences University for the support extended to carry out the work. Our sincere acknowledgement to Dr. Ajith, Senior Veterinary Surgeon, District Veterinary Centre, Kollam, and Dr. N. Divakaran Nair, Professor (Retd), Department of Veterinary Pathology, College of Veterinary and Animal Sciences, Mannuthy, for helping with sample collection and histopathological interpretation respectively.

\section{References}

Bancroft, J.D. and Gamble, M. 2008. Theory and Practice of Histological Techniques. 6th edn. Churchill Livingstone, United States of America, p. 725.

Folmer, O., Black, M., Hoeh, W., Lutz, R. and Vrijenhoek, R. 1994. DNA primers for amplification of mitochondrial cytochrome $c$ oxidase subunit I from diverse metazoan invertebrates. Mol. Mar. Biol. Biotechnol. 3, 294-299

Grzybowska-Szatkowska, L. and Slaska, B. 2012. Mitochondrial DNA and carcinogenesis (Review). Mol Med Rep. 6: 923-930.

Haakensen, V.D., Bjoro, T., Lüders, T., Riis, M., Bukholm, I.K., Kristensen, V.N., Troester, M.A., Homen, M.M., Ursin, G., Borresen-Dale, A.L., et al. 2011. Serum estradiol levels associated with specific gene expression patterns in normal breast tissue and in breast carcinomas. BMC Cancer., 11: 332. 
Miyazono, F., Schneider, P.M., Metzger, R., Warnecke-Eberz, U., Baldus, S.E., Dienes, H.P., Aikou,T and Hoelscher AH. 2002. Mutations in the mitochondrial DNA D-Loop region occur frequently in adenocarcinoma in Barrett's esophagus. Oncogene. 21:3780 3783.

Omasanggar, R., Yu, C.Y., Ang, G.Y., Emran, N.A., Kitan, N., Baghawi, A., Ahmad, A.F., Abdullah, M.A., The, L.K. and Maniam, S. 2020. Mitochondrial DNA mutations in Malaysian female breast cancer patients. PLoS ONE 15(5): e0233461.

Petros, J.A., Baumann, A.K., Ruiz-Pesini,
E., et al., "MtDNA mutations increase tumorigenicity in prostate cancer. In: Proceedings of the National Academy of Sciences of the United States of America,2005, vol. 102, no. 3, pp. 719724.

Slaska, B., Grzybowska-Szatkowska, L., Nisztuk, S., Surdyka, M. and Rozanska D. 2015 Mitochondrial DNA polymorphism in genes encoding ND1, COI and CYTB in canine malignant cancers. Mitochondr DNA.26:452-8.

Warburg, O. 1956. On the origin of cancer cells. Science. 124: 269-270 